\title{
EXPERIMENTAL METHODS USED AS A BASIS FOR DETERMINING MAXIMUM ALLOWABLE GONGENTRATIONS
}

\author{
J. M. BARnES \\ Toxicology Research Unit, M.R.C. Laboratories, Carshalton, U.K.
}

This paper is not concerned with the definition or function of a maximum allowable concentration (M.A.C.) or other "permitted level" of a toxic material in the air. Instead, its purpose is to consider critically the experimental methods used to determine the effects of inhaled materials upon laboratory animals. The literature selected for review is that of the experimental work which is referred to in the Hygiene Guides now appearing regularly in the American Industrial Hygiene Association Quarterly. Data on 52 gases, vapours and dusts have so far been provided and the M.A.C. is given. According to the authors of these guides these M.A.C.'s have been based as follows:
Data on man
19 substances
Data on animals
8 substances
Data on man and animals
25 substances

Figures on a more extensive series show that animal data was used in 56 per cent of a total of 223 substances considered ${ }^{1}$. Insome cases, the M.A.C. is based solely on human comfort and bears no relation to the systemic toxicity of the material. In other cases there is a simple accurate clinical test, such as the determination of a metabolite in urine or enumeration of the white blood cells, which has been used to detect effects in exposed people and so to calculate a safe atmospheric level in working environments.

In many instances there is a considerable amount of data on the atmospheric levels which do or do not affect animals, together with some information on the effects of the same substance on man. This may do no more than indicate that exposure to those levels which have been calculated to be safe for animals has not produced toxic effects in man. However, there is some recent evidence that, if the clinical examination of exposed workers is carried out more critically, then effects may be detected in people who have been exposed to atmospheric levels previously considered to be $\mathbf{s a f e}^{2,3}$. If the animal experiments give a satisfactory picture of a minimal response at one dose and no response at a dose that is somewhat smaller, it is then simple to calculate the M.A.C. for the animals. The "hygiene standard" for exposed men can be set at some appropriate fraction of this level after allowing for such factors as the possible differences in sensitivity between animals and man, variations in sensitivity among the human population and any other general factors which may be thought desirable. Clearly it is 


\section{J. M. BARNES}

important that this superstructure of calculations and extrapolations shall have as sound a foundation as possible. The latter will depend entirely upon the accuracy with which we can detect the least effective dose in our animals.

This paper is based upon an examination of the experimental data as reported and draws conclusions as to whether or not existing methods do enable an investigator to determine accurately the M.A.C. of a compound for laboratory animals. H. F. Smyth ${ }^{4}$, in a review of a great number of compounds to which M.A.C.'s were currently assigned, concludes that, in the great majority of cases, this has been soundly based. His standards are perhaps not very high (e.g., " enough to prevent definite narcosis" or "low enough to prevent lung or kidney injury") when compared with those suggested as being necessary by the study of workers exposed to trichlorethylene. $^{3}$ It seems likely that, until detailed clinical investigations have been carried out on workers exposed to many more different toxic vapours and dusts, it will be necessary to use the standards based on animals which, as Smyth indicates, are enough only to predict confidently that gross toxic effects will not occur. Thus, in the case of carbon tetrachloride, it had been shown that liver cell changes did take place at the level recommended as a permissible concentration. However, the liver cell changes did reverse even under continued exposure ${ }^{5}$. Obviously this level would never have been considered safe had this reversal not happened, but by modern standards this cannot be considered a desirable minimum.

Some technical points in the exposure and examination of experimental animals will now be considered in detail.

\section{TEGHNIQUES OF EXPOSURE}

The need to deliver an exact quantity of a toxic vapour or dust into the air breathed by the experimental animal has led to the design of a number of devices, differing somewhat in detail but each essentially fulfilling its purpose. No one now questions the need for maintaining a dynamic equilibrium in the atmosphere breathed by the animals. This is achieved by using a chamber through which flows a constant stream of air to which the toxic material is added. There is also general agreement that the concentration in the air shall be measured by some suitable sampling and analytical technique and must never be assumed on the basis of simple calculations of the amount volatilized into a given space. Without wishing in any way to detract from the value, scientifically speaking, of being able to maintain constant air concentrations, it is perhaps worth noting that, in emphasizing this constancy of the atmosphere to which the animals were exposed, the experimenter is departing in an important respect from the situation met in the working environment where exposure almost inevitably fluctuates. While all field work points to the importance of this variation in atmospheric concentration, it is unusual for an experimenter to try the effects of such. fluctuation upon his laboratory animals. To consider varying the concentration for different periods inevitably creates many possible permutations and combinations of the dose schedules so that comparisons between observations in different laboratories would become even more difficult than they 
are already. Nevertheless there would appear to be some value in finding out whether the recovery of an animal exposed for a short time to a known toxic level is influenced by the fact that it remains in a lower and, by itself, an ineffective concentration as compared with the recuperative effect of a more permanent removal to fresh air. The expression "chronic toxicity" comes more and more to imply the effect of small doses for very long time whereas a true chronic effect is one which persists after a single damaging dose from which recovery is incomplete. Little is known about the comparative recuperative powers of damaged tissues in experimental animals as compared to man. There is a suggestion that in the case of liver poisoning it is necessary to give repeated damaging doses before cirrhosis in the rat liver can be produced, whereas severe fibrosis after a single insult, such as a viral hepatitis, can occur in man. Similarly the lungs of the rat can recover remarkably well from a very damaging dose of nickel carbony ${ }^{6}$ though not, apparently, so well from hydrogen fluoride. ${ }^{7}$ Man, on the other hand, may apparently suffer permanent disability from one severe exposure to chlorine as in World War I. Concurrent infection may play a part in determining the difference in this response. At any rate it would be wise not to put too much weight on observations showing that chronic effects from single damaging doses of a substance did not develop in experimental animals.

\section{INFLUENCE OF THE EXPOSURE GHAMBERS}

Some, but not all, investigators have realized the need for having two sets of control animals. The first is kept in chambers identical with exposure chambers except that air only flows through them, while the second group of controls remains in cages in the Animal Rooms. There seems little doubt that the daily removal and incarceration of animals can affect their growth and well being, and it is important that this should be assessed in the experiments.

Papers describing the repeated exposure of animals for 8 hours daily for many months frequently refer to deaths from lung infection and epidemics of pneumonia. Such occurrences are often dismissed as an unfortunate or inevitable complication of the experiment. There is not enough published information to indicate whether the keeping of two control groups as described above can throw more light on this problem. Thus, unless care were taken, cross-infection in the Animal Room might result from the nightly re-introduction of the exposed groups. It seems very probable that repeated confinement in chambers may either raise the susceptibility of the animals to infection or increase the chances of an infection spreading from animal to animal. It might be worth further study to see whether the susceptibility of the animal to infection could be raised by exposure to the agent being examined. Thus, changes in the secretion or composition of nasal and respiratory mucous, damage to bronchial cilia or injury to the cells lining the lung alveoli might readily increase the capacity of a microorganism to invade or colonize the injured respiratory tract. Again, a decrease in the animal's natural resistance might result from a liver injury not gross enough to be visible to the pathologist but perhaps subtle enough to interfere with, for example, gamma globulin formation. It might be 


\section{J. M. BARNES}

valuable to try to obtain the consensus of opinion as to whether the occurrence of respiratory infection in animals exposed to toxic vapour and gases was merely an unwelcome complication of the experiments or whether a search for a more specific cause of such infections might be worth undertaking. In the case of ozone it has been expressed ${ }^{8}$ quite categorically that " it is a common finding to observe that exposures to ozone bring out or activate latent subclinical respiratory infections in animals resulting in a full-blown respiratory disease that often ends fatally". No one has suggested using such precautions as, for example, prophylactic sprays of antibiotics, though they might influence any pathological lesions in the livers of animals poisoned by the vapours under test. The addition of antibiotics could not be recommended without stressing the need for a full assessment of their effects other than on the incidence of infections. Finally, it might be worth considering whether the deliberate introduction of an infection and observations on its spread among the animals might provide a sensitive test for the effect of a respiratory tract irritant. This might perhaps also be of some practical interest in relation to factory workshop conditions. The presence or absence of an effect on susceptibility to a respiratory infection deliberately introduced might serve to distinguish substances which act primarily on the respiratory tract tissues from those whose sole action is a systematic one arising after their absorption through the lungs.

The frequency and "nuisance value" of the incidence of lung infection in rats, guinea pigs and rabbits exposed to toxic solvents does suggest that more work along the lines suggested above might produce useful results.

\section{GRITERIA INDIGATING RESPONSE TO TOXIG SUBSTANGES}

In a brief review of the findings in tests on more than 200 substances of different chemical constitution, Smyth et al. ${ }^{9}$ included 31 tests involving repeated inhalation. They found that conclusions based on 5 criteriamortality, weight gain, relative liver weight and kidney weight and macroscopic pathological change were not affected by including the results of a study of other changes such as blood and urine chemistry, blood cytology and histological changes. Unless any one of these criteria prove to be extremely sensitive as a response to a toxic material, this suggests that tests of this kind will detect only severe reactions.

\section{Mortality}

It is reasonable to assume this is the crudest criterion of all and certainly it is rarely the only effect observed. Ethylene dichloride is an example where the animals either die or appear to remain quite normal ${ }^{10}$; it is not surprising to read that nothing is known about its mode of action. ${ }^{11}$ It may be reasonably assumed that whatever its toxic effect may be this is capable of being rapidly and completely reversed. Hydrazine is another compound of a completely different type where death or no effect at all seem to be sequels to exposure of experimental animals ${ }^{12}$.

\section{Depression of growth}

This may result from a lower food uptake or less efficient food utilization. Usually no attempt is made to separate these effects in inhalation studies. 


\section{EXPERIMENTAL METHODS FOR DETERMINING-M.A.C.'s}

The effect on growth is often only a temporary one, though the subsequent growth curve may appear seriously distorted if small changes occur early in life. There is little to indicate whether this early effect represents a greater sensitivity of young animals, or perhaps a higher air intake in proportion to body size or whether the later recovery indicates adaptation to the toxic environment with a fuller development of detoxication mechanisms. A persistent effect on growth appears to be an indication of a major toxic effect. It would be interesting to know whether a failure of appetite and a lower food intake is a reflection of damage to the CNS, to the alimentary tract or to the large organs such as the liver. Thus, in the case of the insecticide dieldrin, a dose of barbiturate will cause a poisoned dog rapidly to regain its appetite ${ }^{13}$.

\section{Liver weight}

Increase in relative liver weight is commonly used as a criterion of toxic response. The histological features of this enlargement have not been very widely discussed but a more detailed account has been given in the case of rats' livers after the chlorinated hydrocarbon D.D.T. ${ }^{14}$ The large liver can be accounted for entirely on the basis of an enlargement of some of its constitutent cells, namely the centrilobular cells. There is no need to postulate cell multiplication to explain the gain in organ weight. The enlarged cells differ mainly in the distribution of their cytoplasmatic ingredients indicated by the expression "increased cytoplasmic oxyphilia with increased basophilia and margination of the cytoplasmic granulations ". This suggests changes in the size and distribution of the mitochondria and modification of the microsomes and cell sap. Further speculation is undesirable in the absence of more precise cytological examinations but this may represent a physiological response to demands for more detoxification as in the coupling of bromobenzene with amino acids or simple chemical degradation. It may reflect a toxic effect of the agent on liver cell mitochondria such as has been described in the case of carbon tetrachloride. ${ }^{15}$ While liver enlargement appears to be a response to an exposure to many toxic chemicals, particularly of the halogenated hydrocarbon group, the sensitivity of the response probably depends upon the nutritional state of the animal, the adequacy of the diet and other factors which would have to be carefully controlled before the best could be got from measuring this response.

\section{Kidney weight}

Less is known about the changes in kidney weight. In rats there may be striking alterations due solely to changes from a natural to a synthetic, though otherwise complete, $\operatorname{diet}^{16}$. Where there is no histological damage indicating gross impairment of function it seems likely that kidney size changes affect the convoluted tubule cells and may again reflect alteration or adjustment in protein metabolism possibly necessitated by detoxication mechanisms removing selected amino-acids.

\section{Histological appearances}

The limited value of detailed pathological accounts on the tissues of elderly rats has been fully discussed in another place ${ }^{17}$. Fortunately, as no one has yet suggested the need for a lifetime study, it is unusual for the 


\section{J. M. BARNES}

rats to be very old at the end of inhalation experiments. It is also true to say that good histological reports supported by adequate photomicrographs are conspicuous by their absence from most papers on inhalation toxicity.

Thus in a brief paper ${ }^{18}$ it is stated that all rats were affected by exposure to the oxides of nitrogen at concentrations ranging from 8-14 p.p.m. daily for 10-24 days. The animals were described as showing severe damage to the respiratory tract which was not proportional to the duration of their exposure. The observation is not in accord with other workers' results, yet the report has apparently been the basis for lowering the M.A.C. of nitrogen dioxide to 5 p.p.m. The same workers later reported ${ }^{19}$ animals entirely unaffected after long exposures to 4 p.p.m. That such a sharp difference in the response of the animal should occur when the concentration falls from 8 p.p.m. to 4 p.p.m. seems improbable and the suspicion that the rats in the earlier experiments were victims of some respiratory disease remains strong. There is a real need for someone to study the earliest persistent histological response in the bronchi and lungs of animals to small doses of irritants. This work is likely to develop now from the current interest in atmosphere pollution with the risk to a much larger population who are exposed to much lower concentrations. If, as discussed above, animals exposed to low concentrations of toxic solvents are more susceptible to respiratory infections, it seems very probable that this will be linked with some cytological or secretory changes in the surface cells of the respiratory tract facilitating colonization of, or invasion by, pathogenic organisms which may reach the bronchi and lungs.

While many substances such as sulphur dioxide are probably toxic solely by vurtue of their irritant action on the lungs, others such as methyl bromide or ethylene dibromide damage both the lungs and the liver. The lung damage may be primary before the substance passes through or may be a reflection of liver damage or caused by a circulating metabolite. There would appear to be a need here for some more study of lung histology to decide whether this organ or the liver is the seat of action of a toxic material such as ethylene dibromide at doses that are only just toxic. Thus Pattle ${ }^{20}$ has described a membrane that possibly exists as no more than a molecular layer which may be responsible, by simple physical forces, in preventing oedema in normal lungs. The effect of toxic substances on this might repay study.

Though much histological work has been done on the liver there are many fewer reports on histological changes in the kidney. It is perhaps less necessary to study the finer changes because renal function studies seem to give a better picture of the capacity of this organ than do similar tests on the liver.

Existing histological methods are notoriously crude instruments for detecting changes in the central nervous system and there is no need to discuss this further. Studies on blood cytology and bone marrow are commonly carried out but except in the case of benzene and its homologues ${ }^{21}$, have yielded little of importance as a diagnostic aid. The anaemia of dogs exposed to beryllium sulphate appears as a solitary exception ${ }^{22}$.

\section{Biochemical tests}

These have usually been based on liver and kidney function studies. According to Smyth et al. ${ }^{9}$, biochemical tests in their experience yielded no 


\section{EXPERIMENTAL METHODS FOR DETERMINING M.A.G.'s}

information that was not given after even smaller doses by measurements of liver and kidney size. The main tests done have been liver lipids, blood phosphatase and blood urea, etc., and plasma prothrombin time. If more were known about the mechanism behind liver cell enlargement, it might be possible to devise more sensitive biochemical tests. For example the detoxication mechanisms residing in the liver cell microsomes might be involved so that a liver function study based on other detoxication reactions might be of value. An example of such a test is the measurement of sleeping times of rats after injection of a short acting barbiturate. Amino-acid incorporation into protein is another important function of liver cell cytoplasm. This might be affected by toxic solvents which produce liver cell enlargement.

\section{Metabolism}

The determination of the excretion of the products of metabolism of a toxic substance is a well accepted method for detecting and estimating exposure. Although such measurements give no direct evidence of actual toxic effects they can furnish a much more accurate gauge of exposure than that provided by the results of intermittent atmospheric sampling in the place of work. One particular aspect of metabolism-the storage in fatmay perhaps have received less attention than it deserves. This is well known for the chlorinated hydrocarbons like D.D.T. and has been demonstrated to be significant in the case of carbon tetrachloride ${ }^{23}$. The ability which a substance possesses for becoming stored in fat may reflect its relative solubility in water and lipid and perhaps play a role in any toxic effects from prolonged repeated exposure. There is not yet any evidence that the presence of a substance in the fat can cause toxic effects on the metabolism of the body lipids.

\section{Species sensitivity}

As in other fields of toxicology there is no general rule to guide the investigator in the choice of a species which will enable him to reproduce the effects in animals that have been, or might be, seen in man exposed to the same substance. Rats, mice, guinea pigs, rabbits, cats, dogs and monkeys have been used to study inhalation toxicity. The guinea pig has a powerful musculature in its respiratory passages, and spasm by irritant materials seems to be more readily produced in this species than in others. Variations in species sensitivity have been recorded for several substances but again no general rule seems to apply. Although the classical work of Lehman and Fleury was carried out mainly on cats or mice, there now is a general tendency to conclude that the reaction of the rat will resemble that of man more closely than that of the guinea pig or rabbit. Others consider that the most sensitive species should provide the guide for extrapolation of animal data to man. This seems reasonable unless there is direct evidence of the effects of human exposure or additional evidence which could explain the special sensitivity of any particular species.

\section{GONGLUSIONS}

Animal tests will continue to provide a basis for assessing the potential toxicity of a substance to which man is liable to be exposed. The size of any permissible concentration in the environment will, in the case of new 


\section{J. M. BARNES}

materials, be based solely on observations made in animal tests. The problem is how to make the tests sufficiently sensitive so that they may be reliable for detecting the earliest noxious effects from the inhalation of a substance.

The following suggestions are put forward for consideration:

(1) As many different species as possible should be exposed to the acute effects of the material. If wide species differences on sensitivity are found, the extrapolation to man must be correspondingly more cautious. It may be necessary to do some extrapolation on the basis of air intake and body size. Thus the $\mathrm{LD}_{50}$ of nickel carbonyl bears the same relation to the size of the animal as the oxygen requirements ${ }^{24}$. If no species differences are found it is suggestive evidence that the toxic material interferes directly with a basic tissue or cellular process. Even this generalization is not absolute as shown by the relatively great sensitivity of the dog to cyanide.

If considerable species differences in sensitivity do exist, this suggests that the compound being administered must first be metabolized and that it is some metabolite which is responsible for its toxic action. It is known that the metabolic attack on. a compound may differ from species as illustrated by the route of the detoxication of benzoic acid in man and the dog.

(2) The short term experiments must be used to determine the main site of action of the toxic substance. In the case of the material we are considering there are three:

(a) a direct irritant and destructive action of the tissues of the respiratory passages and the lungs;

(b) a narcotic action presumably on the central nervous system;

(c) a toxic action on the liver and/or kidneys.

Combination of effects $(a)+(b),(a)+(c),(b)+(c)$, and $(a)+(b)+(c)$ can occur but it is useful to try to decide where the most detailed search for toxic reactions shall take place. Where the primary damage is in the respiratory tract this suggests that the inhaled material reacts immediately either with moisture or the proteins on cell surfaces. Acid fumes are an obvious example of such irritants. The behaviour of new compounds could probably be predicted from a knowledge of how readily they would react with protein or other cell constituents so as to determine whether the toxic reaction is likely to be confined to the first living tissues which they encounter. It may, of course, be quite impossible to suggest where the most important site of action lies, as for example, ethylene dichloride, where the animals show only progressive weakness and no tissue changes.

(3) Repeated exposures must be given in order to study cumulative effects. There seems no good reason for prolonging such tests for more than 2-3 months unless changes such as weight loss and deaths are first seen only at that time. Instead of continuing exposures to the same concentrations for long periods more observations should be made on the effect of a severe, non-fatal dose in increasing susceptibility to lower doses or the effect of prolonged exposure to lower doses on the recovery from the effects of a severe dose. The effect of repeated injury and the nature and completeness of the repair of damage to the lungs or liver are important in evaluating the hazards 


\section{EXPERIMENTAL METHODS FOR DETERMINING M.A.G.'s}

likely to arise from any accidental exposures. The longer the exposures are carried out under the usual experimental conditions so much the greater is the chance that adventitious infections may arise and confuse the observations.

(4) Mortality, growth rate or body weight change, and relative weight of liver and kidney are essential first criteria of poisoning. Improvements might be made along the following lines depending on the nature of the most important site of action.

(a) In the lungs more attention should be paid to the earliest lung and respiratory tract lesions. Young animals exposed for 4-5 periods of 6-8 hours should be used as a starting point. There is a need for more information on the microscopical changes which denote the minimum lung damage to irritant gases. The possibility of reproducing the pathological changes simulating chronic bronchitis in man has not yet been adequately explored. Function studies, such as gas transfer, might be considered. An earlier reference was made to the possible role of respiratory tract irritants in awaking or enhancing the effects of pathogenic bacteria. Controlled infections must be used for the study of any such effects. This is a new field and its value or importance cannot be assessed.

(b) For those substances acting on the CNS, pathology and biochemistry seem to have little to offer as means of detecting minimal effects. Tests of function-behaviour studies, etc.--appear likely to offer most help. Tests of this type have certainly found little place in American or British literature on toxicology. In one study, a revolving drum was used and disclosed that rats showed a much reduced activity after exposure to a concentration of dichlormethane that had no other obvious effect ${ }^{25}$. Sluggishness was also noted as the only sign of poisoning at certain concentrations of hydrazine ${ }^{\mathbf{1 2}}$. Activity itself may increase susceptibility as in the case of ozone ${ }^{26}$ so that tests of behaviour must be designed to control such possibilities as this.

(c) For those materials damaging the liver and kidneys, organ weight changes, though apparently crude, have been shown to be as sensitive a method as can be suggested for detecting poisoning. Much more information is needed upon the mechanisms by which materials like the chlorinated hydrocarbons cause liver cell damage. Very little is known about their metabolism in the liver and it is possible their action is a direct one on the surface of liver cell mitochondria; cytology may be a help here. It seems reasonable to conclude that a dose of any substance that demands an increase in liver cell size to dispose of it safely is too large a dose to be permitted as a daily intake for man. It is perhaps important to stress that most of the work on liver size and liver cell changes has been done on rats, and it is known that in the case of D.D.T. at least, the rat is more sensitive to this type of reaction than the other common laboratory species. Kidney studies are scarcely more advanced. Some evidence on rats shows that the simple urinary concentration test is at least as sensitive an index of kidney damage as the more complex glomerular filtration and tubular reabsorption tests ${ }^{16}$.

\section{Extrapolation from animal tests}

The minimum lethal dose, the maximum non-fatal dose and the maximum dose without any adverse effects at all vary in relation to one another from 


\section{J. M. BARNES}

substance to substance. Similarly the effects of changes in duration of the exposure effect the slope of dose response curves of this kind. ${ }^{27}$ Thus a big difference between the non-effective dose and the lethal dose will indicate that the safe level for repeated exposure must be far removed from a toxic dose because of the risk of persistent tissue damage with long exposure. Where these doses all approximate this suggests rapid excretion or metabolization into harmless products. Safety here may depend on the nature of the lesion produced by a toxic dose. If the substance acts primarily as a narcotic it seems likely that the gross effects at any rate will be rapidly reversible, and that habituation to some extent will probably occur. In man relatively small changes in behaviour may indicate obvious intoxication, but such changes, if they occurred in laboratory animals, would go undetected in the course of an ordinary toxicity test. It would be interesting to know whether these finer changes in behaviour after repeated mild intoxication by a narcotic were always rapidly and completely reversed when exposure had stopped. If the toxic substance primarily damages the liver, the nature and reversibility of the histological changes from the smallest detectable toxic doses must be determined. While the rat liver can regenerate and recover completely from quite severe damage from chlorinated hydrocarbons there are substances, though none yet included in industrial chemicals, which can, from a single dose, produce a slowly progressive liver damage. What are urgently needed here are sensitive function tests and these are likely to be evolved only when their performance involves the use of the same biochemical mechanisms that are injured by, or involved in, the metabolism of the toxic material whose properties are being studied.

Progress in this field will depend upon our making a closer study of the animals and learning more about the biochemical changes that follow the introduction into the animal of a toxic material.

\section{References}

${ }^{1}$ H. E. Stokinger. Am. Ind. Hyg. Assoc. Quart., 17, 284 (1956)

2 A. Andersson. Acta Med. Scand., 157, Suppl., 323 (1957)

${ }^{3}$ E. Grandjean, R. Mynchinger, V. Turriman, P. A. Haas, H-K. Knoepfel and H. Rosenmund. Brit. F. Ind. Med., 12, 131 (1955)

4. F. Smyth. Am. Ind. Hyg. Assoc. Quart., 17, 129 (1956)

${ }^{5}$ H. F. Smyth, H. F. Smyth Jr. and C. P. Carpenter. F. Ind. Hyg. Toxicol., 18, 277 (1936)

' J. M. Barnes and F. A. Denz. Brit. F. Ind. Med., 8, 117 (1951)

7 W. Mackle, F. Thamann, K. Kitzmiller and J. Cholak. F. Ind. Hyg., 16, 129 (1934)

${ }^{8}$ H. E. Stokinger. A.M.A. Arch. Ind. Health, 15, 181 (1957)

${ }^{9}$ H. F. Smyth, S. Weil, E. M. Adams and R. L. Hollingsworth. A.M.A. Arch. Ind. Health. 6, 32 (1952)

${ }^{10}$ H. C. Spencer, V. K. Rowe, E. M. Adams, D. D. McCollister and D. D. Irish. Arch, Ind. Hyg. Occupational Med., 4, 482 (1951)

${ }^{11}$ L. A. Heppel, P. A. Neal, T. L. Perrin, K. M. Endicott and V. T. Porterfield. 7. Ind. Hyg. Toxicol., 28, 113 (1946)

12 C. C. Cornstock, L. H. Lawson, E. A. Greene and F. W. Oberst. A.M.A. Ind. Health, 10, 476 (1954)

${ }^{13}$ W. J. Hayes, F. F. Ferguson and J. S. Cass. Am. J. Trop. Med., 31, 519 (1951)

14 O. G. Fitzhugh and A. A. Nelson. 7. Pharmacol. Exp. Therap., 89, 18 (1947)

15 G. S. Christie and J. D. Judah. Proc. Roy. Soc. (London), B142, 241 (1954)

${ }^{16}$ M. Sherratt. M. Sc. Thesis, Birmingham University, (1958)

${ }^{17}$ J. M. Barnes and F. A. Denz. Pharmacol. Revs., 6, 191 (1954)

${ }^{18}$ E. L. Gray, J. K. MacNamee and S. B. Goldberg. Arch. Ind. Hyg. Occupational Med., 6, $20(1952)$ 


\section{EXPERIMENTAL METHODS FOR DETERMINING M.A.C.'s}

${ }^{19}$ E. L. Gray, S. B. Goldberg and F. M. Patton. Arch. Ind. Hyg. Occupational Med., 10, 423 (1954)

${ }^{20}$ R. E. Pattle. Proc. Roy. Soc. (London), B148, 217 (1958)

${ }^{21}$ H. W. Gerarde. A.M.A. Arch. Ind. Health., 13, 468 (1956)

${ }^{22}$ H. E. Stokinger, G. F. Sprague, R. H. Hall, N. J. Ashenburg, J. K. Scott, and L. T. Steadman. Arch. Ind. Hyg. Occupational Med., 1, 379 (1950)

${ }^{23}$ D. D. McCollister, W. H. Beamer, G. J. Atchison and H. C. Spencer. F. Pharmacol. Exp. Therap., 102, 112 (1951)

${ }_{24}$ J. F. Kincaid, J. S. Strong and F. W. Sunderman. A.M.A. Arch. Ind. Health, 8, 48 (1953)

${ }^{25}$ L. A. Heppel and P. A. Neal. F. Ind. Hyg. Toxicol., 26, 17 (1944)

${ }^{26}$ H. E. Stokinger, W. D. Wagner and P. G. Wright. A.M.A. Arch. Ind. Health, 14, 158 (1956)

${ }^{27}$ E. M. Adams, H. C. Spencer, V. K. Rowe, D. D. McCollister and D. D. Irish. Arch. Ind. Hyg. Occupational Med., 6, 50 (1952) 